\title{
Influence of Dietary Fiber Addition on the Properties of Probiotic Yogurt
}

\author{
T. Ozcan and O. Kurtuldu
}

\begin{abstract}
In this study, the effects of using dietary fiber barley and oat $\beta$-glucan as a prebiotic on the viability of Bifidobacterium bifidum in probiotic yoghurt and properties of yogurt during storage were investigated. The survival of $B$. bifidum was within biotherapeutic level ( $>7 \mathrm{log} \mathrm{cfu} / \mathrm{g})$ as a result of the prebiotic effect of barley and oat based $\beta$-glucan. The addition of $\beta$-glucan to yogurt significantly affected physicochemical properties including $\mathrm{pH}$, titratable acidity (LA \%), whey seperation, color $\left(L^{*}, a^{*}, b^{*}\right)$ and sensorial properties of yogurts. In conclusion, $\beta$-glucan can be used on the development of cereal-based functional dairy products with sufficient viability and acceptable sensory characteristics.
\end{abstract}

Index Terms-Yoghurt, probiotic, dietary fiber, $\beta$-glucan.

\section{INTRODUCTION}

Yogurt is a functional dairy product known for its therapeutic, nutritional, and probiotic effects. It is produced by fermentation of milk with the thermophilic homofermentative lactic acid bacteria Streptococcus thermophilus and Lactobacillus delbrueckii ssp. bulgaricus [1]. During recent years, an increasing interest has developed in foods that contribute to a positive effect on health beyond their nutritional value. Among these functional foods, much attention has been focused on probiotic products and food containing dietary fiber [2]-[4].

Probiotics can be defined as living microorganisms that have proved beneficial effects on health of the host and that improve the intestinal microbial balance [5], [6]. Benefitial effects of probiotics include improving the gut microbial balance, stimulation of the immune system, reduction of blood cholesterol level, and reduction in the incidence of cancer, cardiovascular diseases, diarrhea and osteoporosis [7]-[11].

One of the approaches to increase the number of probiotic bacteria in the intestinal microbiota is including prebiotics in food systems, which are non-digestible dietary fiber components, mainly carbohydrates [12]-[14].

Dietary fibre is naturally present in cereals, vegetables, fruits, and nuts. Based on their simulated intestinal solubility, dietary fibres are either classified as soluble or insoluble fibre. Soluble fibres include pectins, beta-glucans, galactomanan gums, and a large range of nondigestible oligosaccharides including inulin; insoluble fibres include lignin, cellulose, and hemicelluloses [15]-[17].

Foods rich in fibre components have high volume with

Manuscript received November 20, 2013; revised February 24, 2014.

Tulay Ozcan is with the Department of Food Engineering, Faculty of Agriculture, Uludag University, Bursa, Turkey (e-mail: tulayozcan@uludag.edu.tr).

Okan Kurtuldu is with the ETI Food Industries A.S., Eskisehir, Turkey. low energy density, and should promote satiation and satiety, and play a role in the control of energy balance. These foods have the capacity of binding bile acids and metabolites of cholesterol that play an important role in digestion and absorption of lipids in the small intestine, lowering blood cholesterol, regulating blood glucose levels for diabetes management, producing short chain fatty acids and promoting the growth of beneficial gut microflora (i.e. as a prebiotic) [18]-[23]. Due to beneficiary health effects the recommended daily intake of fiber is about $38 \mathrm{~g}$ for men and $25 \mathrm{~g}$ for women [24].

Fiber can be used for improvement of some functional properties such as texture, water holding capacity, oil holding capacity, emulsification and/or gel formation, bulking agent in reduced-sugar applications, and shelf-life of processed foods [25]-[27].

Among the different rich in fibre-foods, cereals are one of the main sources of dietary fibres. Cereal grains, especially oat and barley, are rich in watersoluble fibers. $\beta$-glucans are unbranched polysaccharides that compose of (1-4) and (1-3) linked $\beta$-d-glucopyranosyl units in varying proportions, anda re the major component of cell wall material in oats (3-7\%) and barley (5-11\%), however, only present in small amounts in wheat $(1 \%)$. $\beta$-glucans decrease, absorption and reabsorption of cholesterol and bile acids, delay digestion of lipids and glucose, lower the glycemic response and decreas the risk of heart disease [28]-[30]. The use of $\beta$-glucan on the properties of yogurt have been demonstrated by Vasiljevic et al. [31]; Sahan et al. [32]; Rosburg et al. [33]; in dairy gels by Sharafbafi [34] and cheese by Konuklar et al. [35] and Volikakis et al. [36].

Dairy products are not a good source of fiber, however, can provide an alternative vehicle for the development of fiber enriched foods. Information concerning the effects of cereal based products on the growth of probiotic microorganisms is very limited. Therefore, the objectives of this study were to investigate the addition of Bifidobacterium bifidum and a synbiotic combination (B. Bifidum with either oat-based or barley-based $\beta$-glucan) on viability of probiotic bacteria and the physiochemical characteristics of probiotic yogurt.

\section{MATERIALS AND METHODS}

\section{A. Materials and Methods}

\section{1) Inoculum and yogurt production}

Starter cultures were prepared for inoculum using the method described by Ozcan et al. [37]. Lyophilized cultures (Chr. Hansen's Laboratorium, Denmark) of Bifidobacterium bifidum Bb-12 and yogurt culture, Streptococcus thermophilus + Lactobacillus delbrueckii subsp. bulgaricus 
cultures were propagated in flasks of autoclaved reconstituted skim milk (10.70\% total solids). To facilitate the activation of $B$. bifidum $\mathrm{Bb}-12,0.05 \% \mathrm{~L}-\mathrm{Cys}-\mathrm{HCl}$ was added to diminish the oxidation-reduction potential of the medium. To stimulate the growth, $2 \%$ glucose and $1 \%$ yeast extract were added. B. bifidum Bb-12 cultures were incubated at $37 \pm 1{ }^{\circ} \mathrm{C}$ for $23 \mathrm{~h}$ under anaerobic conditions by the Anaerobic System Anaerogen (Oxoid), whereas yoğurt culture was incubated at the $42 \pm 1^{\circ} \mathrm{C}$ for $3 \mathrm{~h}$ under aerobic conditions, respectively. The necessary inoculum, to give approximately 8 or $9.0 \log _{10} \quad \mathrm{cfu} \mathrm{g}^{-1}$ in yogurt after inoculation, was calculated.

Skim milk powder was reconstituted in distilled water at $10.70 \%(\mathrm{wt} / \mathrm{v})$ to yield reconstituted skim milk of the same overall composition as the raw skim milk and oat (Functional Foods Research Unit, National Center for Agricultural Utilization Research, IL/ USA) and barley based $\beta$-glucan (Naturex, France) at a level of $0,1 \%$ as a prebiotic were added to yogurt mixes. The yogurt mixes were then heat-treated at $90^{\circ} \mathrm{C}$ for $10 \mathrm{~min}$ prior to inoculation. Milks, used in production of yoghurt, were inoculated with $3 \%$ yogurt starter culture (C -control) and B. bifidum $\mathrm{Bb}-12$ (B - B. bifidum, OB -oat based $\beta$-glucan, BB-barley based $\beta$ glucan) as probiotic culture, and were incubated in $42^{\circ} \mathrm{C}$ and $37^{\circ} \mathrm{C}$, respectively to reach $10^{7}-10^{8} \mathrm{cfu} \mathrm{ml} l^{-1}$, until the final $\mathrm{pH}$ value reached 4.8 and 4.6. The yogurts, produced in three replicates, were kept at room temperature $\left(20^{\circ} \mathrm{C}\right)$ for $30 \mathrm{~min}$., stored at $4 \pm 1^{\circ} \mathrm{C}$ and assessed during 28 days of storage.

\section{2) Enumeration of microorganisms}

Probiotic bacteria were enumerated at the beginning and at the end of the fermentation, and on 1, 7, 14, 21 and 28 days of storage. MRS specific lactic agars (Fluka, Germany) were used to enumerate viable cells of B. bifidum. The plates were incubated at $37^{\circ} \mathrm{C}$ for $72 \mathrm{~h}$ under anaerobic conditions [38]. Cell counts were expressed in logarithm per gram of product $\left(\log _{10} \mathrm{cfu} \mathrm{g}^{-1}\right)$, being the geometrical mean of at least three plates. Viability proportion index (VPI) of probiotic microorganisms was calculated as following [39]:

$$
\begin{gathered}
\text { VPI }=\text { Final cell population }\left(\log _{10} \mathrm{cfu} \mathrm{g}^{-1}\right) / \text { initial cell } \\
\text { population }\left(\log _{10} \mathrm{cfu} \mathrm{g}^{-1}\right)
\end{gathered}
$$

\section{3) Physicochemical and sensory analysis}

In yoghurt samples physicochemical parameters as $\mathrm{pH}$, titritable acidity (LA\%) [40], whey separation [41], color values $\left(L^{*}, a^{*}, b^{*}\right) \quad[42]$, and sensory parameters as appearance, texture, odor, color, taste and total acceptability values [43], were recorded throughout the storage of 28 days. The data from each experiment were analyzed by analysis of variance (ANOVA) using SAS software [44] and the differences observed among the treatments were determined by the LSD test at $p<0.01$.

\section{RESUlTS AND DISCUSSION}

Table I shows the viability and viability proportion index (VPI) of B. bifidum in probiotic yogurt samples at the end of fermentation. The VPI of probiotic yogurt fortified with $\beta$ glucan (0.98) was significantly higher than yogurts B and OB $(p<0.01)$.
TABLE I: VIABILITY OF PROBIOTIC MICROORGANISMS AND THEIR RELEVANT VIABILITY PROPORTION INDEX IN DIFFERENT TREATMENTS AT THE END OF FERMENTATION

\begin{tabular}{|c|c|c|c|}
\hline $\begin{array}{c}\text { Yogurt } \\
\text { Type }\end{array}$ & $\begin{array}{c}\text { Initial population } \\
\left(\log _{10} \mathrm{cfu} \mathrm{g}^{-1}\right)\end{array}$ & $\begin{array}{c}\text { Final population } \\
\left.\left(\log _{10} \mathrm{cfu} \mathrm{g}\right)^{-1}\right)\end{array}$ & VPI \\
\hline B & $9.33^{\mathrm{a}}$ & $8.95^{\mathrm{b}}$ & $0.96^{\mathrm{b}}$ \\
\hline BB & $9.42^{\mathrm{a}}$ & $9.30^{\mathrm{a}}$ & $0.98^{\mathrm{a}}$ \\
\hline OB & $9.10^{\mathrm{b}}$ & $8.78^{\mathrm{b}}$ & $0.96^{\mathrm{b}}$ \\
\hline
\end{tabular}

VPI, Viability proportion index.

B: yogurt containing B. bifidum, BB: yogurt containing B. bifidum and barley-based $\beta$-glucan, OB: yogurt containing $B$. bifidum and oat-based $\beta$ glucan

Fig. 1 shows the viability of $B$. bifidum in yogurt containing $\beta$-glucan during 28 days of cold storage per 7-day intervals. Results demonstrated that Bifidobacterium growth and viability were greatly enhanced by $\beta$-glucan supplementation, and $\mathrm{B}, \mathrm{BB}$ and $\mathrm{OB}$ yogurts found to contain sufficient levels of probiotic bacteria to obtain the desired therapeutic impact after 28 days of storage; with final counts of 7.53, 7.76 and $7.47 \log _{10} \mathrm{cfu} \mathrm{g}^{-1}$, respectively. These results were in agreement with Vasiljevic et al. [31], Rosburg et al. [33], and Elsanhoty et al. [45], who reported an increase in probiotic bacteria growth in yogurts supplemented with $\beta$-glucan. The highest viable numbers of $B$. bifidum were observed in the yogurt made with barleybased $\beta$-glucan (BB) (Fig. 1).

Viable counts of $B$. bifidum at day 7 were significantly higher than the viable counts for the other days of storage. There was not significant difference between microbial counts at days 14, 21 and 28. The content of viable probiotic microorganisms decreased during storage, and the rate of this loss is dependent on the type of yogurt and whether a lactic starter culture was used or not [46]. Thus, in order to display the expected health benefits in the gastro-intestinal tract it has been suggested that fermented dairy products should contain probiotic bacteria at $10^{7} \mathrm{cfu} \mathrm{m}^{-1}$ at the time of consumption [47]. Due to the poor growth of bifidobacteria in milk, it is generally recommended that their inoculation level in fermented milk should be that of the desirable level of the probiotic culture in the final product. However, increased inoculum does not guarantee viability of bifidobacteria during fermentation and storage of fermented milk, which has been described as variable depending on the species and supplements added [48], [49].

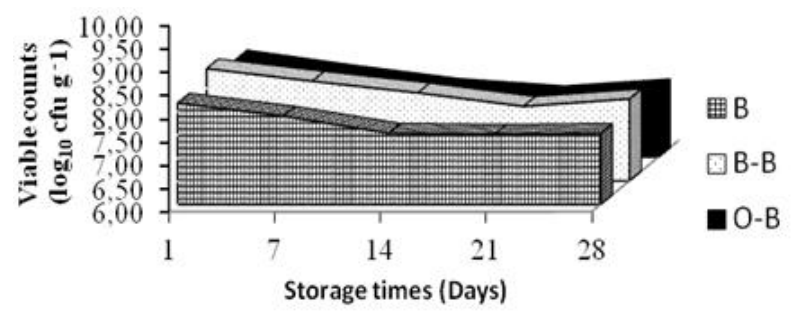

Fig. 1. Viability of $B$. bifidum in probiotic yogurt during storage.

C: control yogurt, B: yogurt containing B. bifidum, BB: yogurt containing $B$. bifidum and barley-based $\beta$-glucan, $\mathrm{OB}$ : yogurt containing yogurt containing $B$. bifidum and oat-based $\beta$-glucan.

Physicochemical properties of probiotic yogurt samples were shown in Table II. Significant differences $(p<0.01)$ were observed in physicochemical properties of yogurt 
samples made from barley and oat-based $\beta$-glucan containing $B$. bifidum. The titratable acidity of $\mathrm{BB}$ yogurt was higher than that of OB yoğurt. These results might be explained byvariations in survival of $B$. bifidum in these yogurts. Whey separation or syneresis is defined as the expulsion of whey from the network which then becomes visible as surface whey and negatively affects consumer perception of yogurt [50]. The supplemantation of $\beta$-glucan significantly decreased whey separation in all yoğurt samples; and this effect could be related to the gelling capacity of $\beta$-glucans and their high ability to cross-link gel network and elastic casein-protein-glucan matrix.

Sensory properties of yogurt have a large effect on consumer acceptability, and especially, color is the first sensory characteristic perceived by the consumer. For the probiotic yogurt, the sensory properties of the products are essential, once they should display similar sensorial acceptance and sensory attributes (texture, aroma, and flavor) of traditional yogurts [51]. Changes in color values $\left(L^{*}\right.$ (lightness), $a^{*}$ (red-green axis), and $b^{*}$ (yellow/blueness) of probiotic yogurt samples were shown in Table II. $(p<0.01)$. The $L^{*}$ value for the control (C) yogurt were significantly higher than the $L^{*}$ values for probiotic yogurt containing barley-based and oat-based $\beta$-glucan. The $a^{*}$ and $b^{*}$ values for all thetreatments were significantly different from each other (Table II).

The sensory properties of yogurt samples were presented in Fig 2. It was noticed that there was a significance difference in sensory properties of yogurts $(p<0.01)$.
Storage time significantly affected color, flavor and taste values of yogurts as depending on variations in microbial counts, $\mathrm{pH}$ and syneresis. Tudorica et al. [52] demonstrated that incorporation of $\beta$-glucans into low fat dairy products can make their mouthfeel, scoopability and sensory properties resemble those of full-fat products. Consequently, yogurt with oat-based $\beta$-glucan (OB) received higher scores for appearance, odor, color, taste, and overall acceptance than did yogurt containing barley-based $\beta$-glucan.

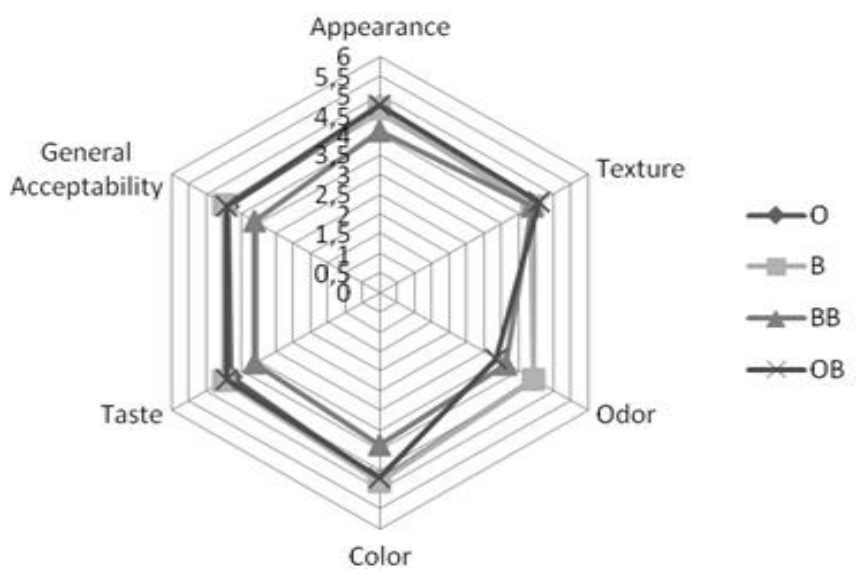

Fig. 2. Average sensory ratings of probiotic yogurts

C: control yogurt, B: yogurt containing B. bifidum, BB: yogurt containing $B$. bifidum and barley-based $\beta$-glucan, OB: yogurt containing yogurt containing $B$. bifidum and oat-based $\beta$-glucan.

TABLE II: THe CHANGES IN PHySIOCHEMICAL PROPERTIES OF YOGURTS DURING STORAGE*

\begin{tabular}{|c|c|c|c|c|c|c|c|}
\hline & \multirow[b]{2}{*}{$\mathbf{N}$} & \multirow[b]{2}{*}{ pH } & \multirow{2}{*}{$\begin{array}{c}\text { Titratable Acidity } \\
\text { (\%LA) }\end{array}$} & \multirow[b]{2}{*}{ Whey Seperation (25 $\mathrm{g} \mathrm{mL}^{-1}$ ) } & \multicolumn{3}{|c|}{ Color values } \\
\hline & & & & & $L^{*}$ & $a^{*}$ & $b^{*}$ \\
\hline \multicolumn{8}{|c|}{ Yogurt Type } \\
\hline $\mathbf{C}$ & 10 & $4.05^{\mathrm{b}}$ & $1.14^{\mathrm{a}}$ & $7.78^{a}$ & $98.30^{\mathrm{a}}$ & $-4.47^{\mathrm{a}}$ & $10.91^{b}$ \\
\hline B & 10 & $4.75^{\mathrm{a}}$ & $0.79^{\mathrm{bc}}$ & $7.01^{\mathrm{b}}$ & $97.45^{\mathrm{ab}}$ & $-4.04^{\mathrm{a}}$ & $11.02^{b}$ \\
\hline BB & 10 & $4.73^{\mathrm{a}}$ & $0.83^{\mathrm{b}}$ & $6.68^{b}$ & $95.00^{c}$ & $-5.43^{b}$ & $13.88^{\mathrm{a}}$ \\
\hline OB & 10 & $4.74^{\mathrm{a}}$ & $0.78^{\mathrm{c}}$ & $7.47^{\mathrm{a}}$ & $97.07^{b}$ & $-4.16^{\mathrm{a}}$ & $11.24^{\mathrm{b}}$ \\
\hline \multicolumn{8}{|c|}{ Storage Time } \\
\hline 1 & 8 & $4.65^{\mathrm{a}}$ & $0.87^{\mathrm{ns}}$ & $8.01^{\mathrm{a}}$ & $94.45^{\mathrm{c}}$ & $-2.33^{\mathrm{a}}$ & $13.10^{\mathrm{a}}$ \\
\hline 7 & 8 & $4.61^{b}$ & $0.90^{\mathrm{ns}}$ & $7.38^{\mathrm{b}}$ & $97.92^{\mathrm{a}}$ & $-4.95^{b}$ & $10.95^{\mathrm{c}}$ \\
\hline 14 & 8 & $4.54^{\mathrm{c}}$ & $0.89^{\mathrm{ns}}$ & $7.04^{\mathrm{bc}}$ & $98.52^{\mathrm{a}}$ & $-5.10^{\mathrm{b}}$ & $11.28^{\mathrm{bc}}$ \\
\hline 21 & 8 & $4.50^{\mathrm{d}}$ & $0.89^{\mathrm{ns}}$ & $6.71^{\mathrm{c}}$ & $97.98^{\mathrm{a}}$ & $-5.23^{b}$ & $10.97^{\mathrm{c}}$ \\
\hline 28 & 8 & $4.54^{\mathrm{c}}$ & $0.88^{\mathrm{ns}}$ & $7.04^{\text {bc }}$ & $95.91^{b}$ & $-5.01^{b}$ & $12.52^{\mathrm{ab}}$ \\
\hline
\end{tabular}

*Values presented are the means of three replicates trials

Significance level: significant at $p<0.01(* *)$, different superscript letters on the same column indicate significant differences, ns: non significan C: control yogurt, B: yogurt containing B. bifidum, BB: yogurt containing B. bifidum and barley-based $\beta$-glucan, OB: yogurt containing yogurt containing B. bifidum and oat-based $\beta$-glucan.

\section{CONCLUSION}

Many studies have focused on the probiotics and prebiotics with health-promoting effects such as prevention of nutrition-related diseases. It is generally accepted that in order to appreciate the therapeutic effects, the probiotic foods should have a minimum concentration of $>10^{7} \log _{10}$ cfu viable cells per $\mathrm{mL}$ or $\mathrm{g}$ of product at the point of consumption. $\beta$-glucan, an alternative prebiotic, is also dietary fiber. Both fiber and probiotics are well known for their beneficial health effects, and together they may constitute a good source of functional foods. In conclusion, supplementation of $\beta$-glucan in yogurt was found to improve the viability and metabolic activity of $B$. bifidum by displaying a prebiotic effect and can be an alternative for 
development of cereal-based functional dairy products.

\section{REFERENCES}

[1] T. Ozcan-Yilsay, W. J. Lee, D. Horne, and J. A. Lucey, "Effect of trisodium citrate on rheological, physical properties and microstructure of yogurt," Journal of Dairy Science, vol. 90, pp. 1644-1652, 2007.

[2] M. Blades, "Functional foods or nutraceuticals," Nutrition and Food Science, vol. 30, pp. 73-75, 2000.

[3] Y. Malkki, "Trends in dietary fiber research and development," Acta Alimentaria, vol.33, pp. 39-62, 2004.

[4] F. Trepel, "Dietary fibre: More than a matter of dietetica. I. Compounds, properties, physiological effects," Wiener Klinische Wochenschrift, vol. 116, pp. 465-471, 2004.

[5] R. Fuller, "Probiotics in man and animals," Journal of Applied Bacteriology, vol. 66, pp. 365-378, 1989.

[6] M. Saarela, G. Mogensen, R. Fonden, J. Matto, and S. T. Matilla, "Probiotic bacteria: Safety, functional and technological properties," Journal of Biotechnology, vol. 84, pp.197-215, 2000.

[7] W. H. Holzapfel and U. Schillinger, "Introduction to preand probiotics," Food Research International, vol. 35, pp. 109-116, 2002.

[8] P. Marteau, and M. C. Boutron-Ruault, "Nutritional advantages of probiotics and prebiotics," British Journal of Nutrition, vol. 87, pp. 153-157, 2002.

[9] M. E. Sanders, "Probiotics: considerations for human health," Nutrition Review, vol. 61, pp. 91-99, 2003.

[10] C. N. Heenan, M. C. Adamsa, R. W. Hoskena, and G. H. Fleet, "Survival and sensory acceptability of probiotic microorganisms in a non-fermented frozen vegetarian dessert," LWT-Food Science and Technology, vol. 37, pp. 461-466, 2004.

[11] D. Samaržija, M. Tudor, T. Prtilo, I. D. Špehar, Š. Zamberlin, and J. Havranek, "Probiotic bacteria in prevention and treatment of diarrhea," Mljekarstvo, vol. 59, pp. 28-32. 2009.

[12] J. Schrezenmeir and M. de Vrese, "Probiotics, prebiotics, and synbiotics approaching a definition," American Journal of Clinical Nutrition, vol. 73, pp. 361-364, 2001

[13] A. Sip and W. Grajek, "Probiotics and prebiotics," in Functional food product development, J. Smith and E. Charter, Eds. Wiley-Blackwell, Ltd., Publication, United Kingdom, 2010, pp. 146-177.

[14] T. S. Manning and G. R. Gibson, "Prebiotics," Best Pract Res Clin Gastroenterol, vol. 18, pp. 287-298, 2004.

[15] A. Desmedt and H. Jacobs, "Soluble fibre," in Guide to functional food ingredientsSurrey, England: Food RA Leatherhead Publishing, 2001, pp. 112-140.

[16] J. Lunn and J. L. Buttriss, Carbohydrates and dietary fibre, British Nutrition Foundation, vol. 32, pp. 21-64, 2007.

[17] K. M. Behall, D. J. Scholfield, J. Hallfrisch, and H. G. M. LiljebergElmstahl. "Consumption of both resistant starch and $\beta$-glucan improves postprandial plasma glucose and insulin in women," Diabetes Care, vol. 29, pp. 976-81, 2006.

[18] M. Velasquez, C. Davies, R. Marret, J. L. Slavin, and J. M. Feirtag, "Effect of oligosaccharides and fibre substitutes on short chain fatty acid production by human microflora," Anaerobe, vol. 6, pp. 87-92, 2000.

[19] E. Theuwissen and R. P. Mensink, "Water-soluble dietary fibers and cardiovascular disease," Physiology \& Behavior, vol. 94, pp. 285-92, 2008.

[20] R. Crittenden, S. Karppinnen, S. Ojanen, M. Jenkanen, J. MattilaSandholm, and K. Poutanen, "In vitro fermentation of cereal dietary fibre carbohydrates by probiotic and intestinal bacteria," Journal of the Science Food and Agriculture, vol. 82, pp. 781-789, 2002.

[21] B. C.Tungland, "Fructooligosaccharides and other fructans: Structures and occurrence, production, regulatory aspects, food applications and nutritional health significance," ACS Symposium Series, vol. 849, pp. $135-152,2003$

[22] C. S. Brennan, and C. M. Tudorica, "The role of carbohydrates and nonstarch polysaccharides in the regulation of postprandial glucose and insulin responses in cereal foods," Journal of Nutraceuticals, Functional and Medical Foods, vol. 4, pp. 49-55, 2003.

[23] C. W. C. Kendall, A. Esfahani, and D. J. A. Jenkins, "The link between dietary fibre and human health," Food Hydrocolloids, vol. 24, pp. $42-48,2010$.

[24] P. Trumbo, S. Schlicker, A. A. Yates, and M. Poos, "Dietary reference intakes for energy, carbohydrate, fiber, fat, fatty acids, cholesterol, protein and amino acids," Journal of the American Dietetic Association, vol. 102, pp. 1621-1630, 2002.

[25] R. Rodri'guez, A. Jime'nez, J. Ferna'ndez-Bolanos, R. Guille'n, and A. Heredia, "Dietary fibre from vegetable products as source of functional ingredients," Trends in Food Science \& Technology, vol. 17, pp. $3-15,2006$
[26] R. Chawla and G. R. Patil, "Soluble Dietary Fiber," Comprehensive Reviews in Food Science and Food Safety, vol. 9, pp. 178-196, 2010.

[27] M. Viuda-Martos, M. C. L'opez-Marcos, J. Fern'andez-L'opez, E. Sendra, J. H. Lo'pez-Vargas, and J. A. Pe'rez-A'lvarez, "Role of Fiber in Cardiovascular Diseases," Comprehensive Reviews In Food Science And Food Safety, vol. 9, pp. 240-258, 2010.

[28] A. Skendi, C. G. Biliaderis, A. Lazaridou, and M. S. Izydorczyk, "Structure and rheological properties of water soluble $\beta$-glucans from oat cultivars of Avena sativa and Avena bysantina," Journal of Cereal Science, vol. 38, pp. 15-31, 2003.

[29] M. S. Buckeridge, C. Rayon, B. Urbanowicz, M. A. S. Tine, and N. C. Carpita, "Mixed linkage $(1 \rightarrow 3),(1 \rightarrow 4)-\beta$-D-glucans of grasses.," Cereal Chemistry, vol. 81, pp. 115-127, 2004.

[30] T. Ozcan, O. Kurtuldu, and B. Delikanli, "The development of cerealbased dairy products using $\beta$-glucan," Journal of Agricultural Faculty of Uludag University, vol. 27, pp. 87-96, 2013.

[31] T. Vasiljevic, T. Kealy, and V. K. Mishra, "Effects of $\beta$-glucan addition to a probiotic containing yogurt," Journal of Food Science, vol. 72, pp. 405-411, 2007.

[32] N. Sahan, K. Yasar, and A. A. Hayaloglu, "Physical, chemical and flavour quality of non-fat yogurt as affected by a $\beta$-glucan hydrocolloidal composite during storage," Food Hydrocolloids, vol. 22, pp. 1291-1297, 2008.

[33] V. Rosburg, T. Boylston, and P. White, "Viability of Bifidobacteria strains in yogurt with added oat beta-glucan and corn starch during cold storage," Journal of Food Science, vol. 75, pp. 5, 439-444, 2010.

[34] N. Sharafbafi, "Structuring Properties of Beta-glucan in Dairy Gels: Control of Phase Separation," A thesis presented to The University of Guelph, p.119, 2012

[35] G. Konuklar, G. Inglett, C. Carrier, and F. Felker, "Use of a $\beta$-glucan hydrocolloidal suspension in the manufacture of low-fat cheddar cheese: Manufacture, composition, yield and microstructure," Internatioanl Journal of Food Science \& Technology, vol. 39, pp. 109115, 2004.

[36] P. Volikakis, C. G. Biliaderis, C. Vamvakas, and G. K. Zerfridis, "Effects of a commercial oat- $\beta$-glucan concentrate on the chemical, physico-chemical and sensory attributes of low-fat white-brined cheese product," Food Research International, vol. 37, pp. 83-94, 2004.

[37] T. Ozcan, L. Yilmaz-Ersan, A. Akpinar-Bayizit, O. I. Sahin, and P. Aydinol, "Viability of Lactobacillus acidophilus LA-5 and Bifidobacterium bifidum BB-12 in rice pudding," Mljekarstvo, vol. 60, pp. 135-144, 2010.

[38] C. G. Vinderola and J. A. Reinheimer, "Culture media for the enumeration of Bifidobacterium bifidum and Lactobacillus acidophilus in the presence of yoghurt bacteria," International Dairy Journal, vol. 9, pp. 497-505, 1999

[39] E. Ahmadi, A. M. Mortazavian, M. R. Fazeli, H. Ezzatpanah, and R Mohammadi, "The effects of inoculant variables on the physicochemical and organoleptic properties of Doogh," International Journal of Dairy Technology, vol. 65, pp. 274-281, 2012.

[40] AOAC, Official Methods of Analysis,17th Ed., Association of Official Analytical Chemistry, Arlington, Virginia, USA. 2000.

[41] H. Wu, G. J. Hulbert, and J. R. Mount, "Effects of ultrasound on milk homogenization and fermentation with yogurt starter," Innovative Food Science and Emerging Technologies, vol. 1, pp. 211-218, 2001.

[42] D. J. McClements, "Colloidal basis of emulsion color," Current Opinion Colloid \& Interface Science, vol. 7, pp. 451-455, 2002.

[43] M. D. Staffolo, N. Bertola, M. Martino, and A. Bevilacqua, "Influence of dietary fiber addition on sensory and rheological properties of yogurt," International Dairy Journal, vol. 14, pp. 263-268, 2004.

[44] SAS, SAS User's guide: statistics, version 9.1 edition, Cary, N.C. SAS Inst. Inc. 2004.

[45] R. Elsanhoty, A. Zaghlol, and A. H. Hassanein, "The manufacture of low fat labneh containing barley $\beta$-Glucan 1-chemical composition, microbiological evaluation and sensory properties," Current Research in Dairy Sciences, vol. 1, pp. 1-12, 2009.

[46] C. G. Vinderola, G. A. Costa, S. Regenhardt, and J.A. Reinheimer, "Influence of compounds associated with fermented dairy products on the growth of lactic acid starter and probiotic bacteria," International Dairy Jornal, vol. 12, pp. 579-589, 2002.

[47] A. C. Ouwehand and S. J. Salminen, "The health effects of cultured milk products with viable and non-viable bacteria," International Dairy Journal, vol. 8, pp. 749-758, 1998.

[48] R. I. Dave and N. P. Shah, "Ingredient supplementation effects on viability of probiotic bacteria in yogurt," Journal of Dairy Science, vol. 81, pp. 2804-2816, 1998

[49] L. Lamoureux, D. Roy, and S. F. Gauthier, "Production of oligosaccharides in yoghurt containing Bifidobacteria and yoghurt cultures," Journal of Dairy Science, vol. 85, pp. 1058-1069, 2002. 
[50] J. A. Lucey, "The relationship between rheological parameters and whey separation in milk gels," Food Hydrocolloids, vol. 15, pp. 603608, 2001.

[51] A. G. Cruz, E. H. M. Walter, R. S. Cadena et al., "Survival analysis methodology to predict the shelf-life of probiotic flavored yogurt," Food Research International, vol. 43, pp. 1444-1448, 2010.

[52] C. M. Tudorica, T. E. R. Jones, V. Kuri, and C. S. Brennan, "The effects of refined barley $\beta$-glucan on the physico-structural properties of low-fat dairy products: curd yield, microstructure, texture and rheology," Journal of the Science of Food and Agriculture, vol. 84, pp. 1159-1169. 2004.

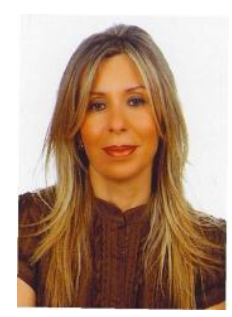

Tulay Ozcan is an associate professor of the Department of Food Engineering at the Uludag University, Bursa, Turkey. More recently, she has worked in the area of rheology and texture of dairy products. From 2005 to 2006 and 2010 (21 months) she worked at University of Wisconsin-Madison USA, Department of Food Science as a visiting scientist. Topics of interest includes dairy chemistry and biochemistry, rheological properties and microstructure of yogurt, texture of yogurt and cheese, the use of dairy and plant based proteins for the production of functional dairy products, probiotics and prebiotics, traditional cheeses and enzyme accelerated ripening of cheese, the use of fat replacer in dairy products and principles of nutrition. 